\title{
Ameliorative Effect of Lycopene on Acrylamide-Induced Hepatotoxicity in Adult Albino Rats
}

\author{
RABAB F. HINDAWY, M.D.* and FATMA F. HENDAWY, M.D.** \\ The Departments of Forensic Medicine \& Clinical Toxicology* and Pharmacology**, Faculty of Medicine, \\ Benha University, Egypt
}

\begin{abstract}
Background: Acrylamide (ACR) is a chemical substance formed when starchy foods, such as potatoes and bread are cooked at high temperatures (above $120^{\circ} \mathrm{C}$ ). It can be formed when foods fried and baked. High acrylamide levels have carcinogenic, genotoxic, neurotoxic and hepatotoxic effects on living organisms.

Aim of Study: The present study designed to illustrate the biochemical and histopathological alterations of ACR on the liver of rats and the treatment of oxidative damage caused by acrylamide with the administration of a strong antioxidant, namely Lycopene (LYC), which is a naturally carotenoid pigment that is widely found in red foods such as tomato, watermelon, papaya, pink grape-fruit, pink guava and carrots.

Material and Methods: Sixty rats were divided into five groups (negative control, positive solvent control, Lycopene (10mg/kg/day), acrylamide $(25 \mathrm{mg} / \mathrm{kg} /$ day $)$, and acrylamide $(25 \mathrm{mg} / \mathrm{kg} /$ day $)+$ Lycopene $(10 \mathrm{mg} / \mathrm{kg} /$ day $))$. Treatment was oral for 6 weeks. The biochemical and histopathological alterations of ACR on the liver of rats and ameliorative effect of lycopene on acrylamide-induced hepatotoxicity were examined.

Results: It was observed that acrylamide administration decreased serum reduced Glutathione (GSH) level when compared to the control group. On the contrary, it was also observed that Aspartate aminotransferase (AST), Alanine aminotransferase (ALT), and Malondialdehyde (MDA) levels increased as a result of acrylamide administration. Histopathological examinations of liver demonstrated dilated congested central vein and sinusoids, inflammatory cell infiltration, and hepatocellular necrosis in ACR group. Furthermore, ballooning degeneration was detected in hepatocytes. After Lycopene treatment, it was observed that GSH level increased while AST, ALT, and MDA levels decreased. All histopathological changes, were ameliorated when Lycopene was coadministered with acrylamide. Conclusion: In the present study, it was demonstrated that Lycopene ameliorates acrylamide induced liver damage due to the strong antioxidant properties of Lycopene.
\end{abstract}

Key Words: Acrylamide - Lycopene - Hepatotoxicity - Rats.

Correspondence to: Dr. Rabab F. Hindawy,

The Department of Forensic Medicine \& Clinical Toxicology, Faculty of Medicine, Benha University, Egypt

\section{Introduction}

ACRYLAMIDE (ACR) is an organic compound with the chemical formula $\mathrm{CH}_{2}=\mathrm{CHC}(\mathrm{O}) \mathrm{NH}_{2}$. It is a white odorless solid, soluble in water and several organic solvents [1]. It is produced industrially as a precursor to polyacrylamides, which find many chemical and industrial applications, e.g., in waste water management, ore processing, cosmetics, paper packaging and molecular laboratories for gel chromatography [2]. In addition, ACR is used as a thickening agent, so it is often absorbed during occupational exposure [3]

The discovery that some cooked foods contain acrylamide in 2002 has attracted significant attention to its possible biological effects, and shown the need for further research into neurotoxicity, hepatotoxicity and reproductive harm, but primarily carcinogenicity [4]

Acrylamide was found in starchy foods such as potato chips (potato crisps), French fries (chips), and bread that had been heated higher than $120^{\circ} \mathrm{C}$ $\left(248^{\circ} \mathrm{F}\right)$. It concerned foods that are regularly consumed throughout the years, like biscuits, crackers and breakfast cereals. Production of acrylamide in the heating process was shown to be temperature dependent. It was not found in food that had been boiled, or in foods that were not heated [ $\boldsymbol{r}$.

Acrylamide arises in some cooked foods via a series of steps initiated by the condensation of the amino acid asparagine and reducing sugars (fructose, glucose, etc.) or reactive carbonyls at temperatures above $120^{\circ} \mathrm{C}\left(248^{\circ} \mathrm{F}\right)$. This condensation, one of the Maillard reactions followed by dehydrogenation produces $\mathrm{N}$-(D-glucos-1-yl)-L-asparagine, which upon pyrolysis generates some acrylamide [6]. 
Cigarette smoking is a major acrylamide source [7]. It causes an increase in blood acrylamide levels three-fold greater than any dietary factor [8] .

Glycidamide, a metabolite of acrylamide, causes cell damage. Prolonged exposure has induced tumors in rats but cancer in man has not been convincingly shown. The International Agency for Research on Cancer (IARC) has classified acrylamide as a probably carcinogenic to humans. High acrylamide levels have genotoxic, neurotoxic and hepatotoxic effects on living organisms [9]. Acrylamide causes oxidative damage [10].

Lycopene (LYC), a bioactive compound is a fat soluble naturally carotenoid pigment that is widely found in red foods such as tomato, papaya, pink grape-fruit, pink guava, carrots and watermelon [11]. The structure of LYC $(\mathrm{C} 40 \mathrm{H} 56)$ is an acyclic isomer of $b$-carotene with 13 conjugated double bond. It is one of the most effective antioxidants in the carotenoid family and its activity against biological reactive oxygen species may prevent or ameliorate oxidative damage to cells and tissues both in vivo and in vitro [12]. It also has the potential of quenching singlet oxygen 100 times more efficiently than Vitamin E and 125 times more than Glutathione (GSH). Furthermore, even at low oxygen tension, it can also scavenge peroxyl radicals, inhibiting the process of lipid peroxidation. It is the most efficient quencher of singlet oxygen among all naturally occurring carotenoids [13].

Lycopene has been shown to have the ability to reduce the risk of cancers, such as breast, prostate and gastric cancer [14] . Additionally, Lyc also exhibited potent neuroprotective, anti-inflammatory, anti-proliferative, maintenance of normal cell metabolism, cognition enhancing properties, regulating blood lipid metabolism and so on [15].

Studies have demonstrated that LYC is a common substance of chemoprevention, preventing the toxicity of a variety of toxicants. The LYC can protect against the toxic effects of Malathion. It also reduced Deltamethrin effects induced thyroid toxicity in albino rats [16]. Nevertheless, whether LYC has the potential to prevent the toxicity of ACR is still unclear.

The current understanding of acrylamide toxic effects on the liver tissues of animals is somewhat limited; therefore, the present study was aimed out to examine the liver of rats, in order to clarify the possible alterations, due to the oxidative stress of acrylamide. Moreover, the objective was to evaluate the ability of Lycopene (LYC) to decrease the toxicity of acrylamide.

\section{Aim of the work:}

The present work was conducted to assess the ameliorative effect of lycopene against acrylamideinduced hepatotoxicity in adult albino rats.

\section{Material and Methods}

\section{I- Material:}

\section{1- Chemicals:}

Acrylamide (ACR) and Lycopene (LYC) were purchased from Sigma Chemical Company. They were given orally for 6 weeks [17]

Acrylamide was given with a daily dose (25 $\mathrm{mg} / \mathrm{kg}$ ). It was prepared immediately before use by dissolving it in distilled water [18]

Lycopene was given with a daily dose (10 $\mathrm{mg} / \mathrm{kg}$ ). It was prepared immediately before use by dissolving it in corn oil [16].

\section{2- Animals:}

The present work was carried out on sixty Wister albino rats (body weight 180-200gm.) which were obtained from the Experimental Animal Center of Helwan (Egypt) during 2 monthes March and April 2019. Every six rats were kept in each cage and were allowed for one week of adaptation before the experiment (taking food \& water without any medications) in their new environment at Anatomy Department, Faculty of Medicine, Benha University.

This research was accepted by the Local Ethical Committee for Scientific Research, Benha Faculty of Medicine, Benha University.

\section{II- Methods:}

Experimental design:

Groups: Sixty rats were randomly divided into 5 groups:

- Group I (negative control): (10 rats) they left without intervention to measure the basic parameters, free access to food and water was allowed for 6 weeks.

- Group II (positive solvent control): (20 rats) rats of this group was subdivided into 2 subgroups:

- Subgroup IIa: (10 rats) they received distilled water (solvent of Acrylamide); $5 \mathrm{ml}$ orally/day for 6 weeks.

- Subgroup IIb (corn oil): (10 rats) they received corn oil (solvent of lycopene); $5 \mathrm{ml}$ orally/day for 6 weeks. 
- Group III (lycopene): (10 rats) rats of this group received lycopene; lycopene was given in a dose $(10 \mathrm{mg} / \mathrm{kg} /$ day dissolved in $5 \mathrm{ml}$ corn oil $), 5 \mathrm{ml}$ given orally/day for 6 weeks [16]

- Group IV (Acrylamide): (10 rats) rats of this group received Acrylamide; Acrylamide was given in a dose $(25 \mathrm{mg} / \mathrm{kg} /$ day dissolved in $5 \mathrm{ml}$ distilled water), $5 \mathrm{ml}$ given orally/day for 6 weeks [18].

- Group V(Acrylamide + lycopene): (10 rats) rats of this group received combination of Acrylamide which was given in a dose $(25 \mathrm{mg} / \mathrm{kg} /$ day $)$ and lycopene which was given in a dose $(10 \mathrm{mg} / \mathrm{kg} /$ day); this combination was given orally for 6 weeks.

Rats were anaesthetized with ether inhalation at the end of the experiment, the abdominal cavity was opened, and blood samples were collected from heart and processed for biochemical measurements. The liver was fixed in $10 \%$ formalin to prepare paraffin sections.

\section{A- Biochemical study:}

Blood samples were obtained from rats, hearts. Samples were centrifuged for $10 \mathrm{~min}$ at 3000r.p.m. Sera were put in the tubes to be tested for:

\section{1- Liver enzymes:}

- Alanine aminotransferase (ALT) level was calculated spectrophotometrically using the commercial test of SGPT (ALT) with spinlab (Spinreact company), Spain.

- Aspartate aminotransferase (AST) level was calculated spectrophotometrically using the commercial test of SGOT (AST) with spinlab (Spinreact company), Spain.

2- Oxidative stress indices: The malondialdehyde (MDA) concentration in blood samples was determined using the method described by Chattopadhyay et al. [19]

3- Antioxidants: Reduced glutathione (GSH) was measured using the method of Beulter et al., [20].

\section{B- Histopathological study:}

Liver specimens were fixed in $10 \%$ formaldehyde buffer, then embedded in paraffin and cut into 5 thesess sections according to the routine procedure. The sections were stained with hematoxylin and eosin (H \& E) for routine histopathological examination, and examined under a light microscope (BX-50; Olympus) according to Lamberg and Rothstein [21].

\section{Statistical analysis:}

The values were expressed as the mean \pm standard deviation (mean $\pm \mathrm{SD}$ ). Differences between groups were assessed by one-way analysis of variance ANOVA (F-test) using the Statistical Package for Social Sciences (SPSS) software package for Windows (Version 21.0) (Spss Inc, Chicago, ILL Company). Post hoc testing was performed for intergroup comparisons using the Least Significant Difference (LSD) test. A value corresponding to $p<0.05$ was considered statistically significant.

\section{Results}

\section{A- Biochemical:}

In the present work negative control, positive solvent control, and lycopene groups, showed a non-significant difference $(p>0.05)$ as regard biochemical parameters (ALT, AST, MDA and GSH), as showed in (Table 1). So, the mean of those groups was chosen as a representative group for the three groups to be compared with the results of the tested groups.

Table (1): Comparison between negative control, positive control, and lycopene groups regarding alanine aminotransferase (ALT), aspartate aminotransferase (AST), malondialdehyde (MDA) and reduced glutathione (GSH).

\begin{tabular}{|c|c|c|c|c|c|c|c|c|}
\hline \multirow{2}{*}{ Groups } & \multicolumn{2}{|c|}{ ALT (U/L) } & \multicolumn{2}{|c|}{ AST (U/L) } & \multicolumn{2}{|c|}{ MDA $(\mathrm{nmol} / \mathrm{ml})$} & \multicolumn{2}{|c|}{$\mathrm{GSH}(\mathrm{mg} / \mathrm{ml})$} \\
\hline & Mean & $\pm \mathrm{SD}$ & Mean & $\pm \mathrm{SD}$ & Mean & $\pm \mathrm{SD}$ & Mean & $\pm \mathrm{SD}$ \\
\hline Group I (negative control) & 24 & 3.3 & 21.8 & 5.9 & 5.55 & 0.05 & 4.60 & 0.21 \\
\hline Grou & 22.4 & 4.8 & 24 & 7.5 & 5.30 & 0.0 & 5.08 & 0.16 \\
\hline Group III (lycopene) & 22.8 & 4 & 25 & 6.5 & 5.4 & 0.02 & 5.06 & 0.27 \\
\hline F-test & \multicolumn{2}{|c|}{1.87} & \multicolumn{2}{|c|}{2.1} & \multicolumn{2}{|c|}{1.6} & \multicolumn{2}{|c|}{1.21} \\
\hline$p$ & \multicolumn{2}{|c|}{$>0.05$ (NS) } & \multicolumn{2}{|c|}{$>0.05$ (NS) } & \multicolumn{2}{|c|}{$>0.05(\mathrm{NS})$} & \multicolumn{2}{|c|}{$>0.05$ (NS) } \\
\hline
\end{tabular}

NS: Non-Significant.

In the present work, it was observed that acrylamide administration high significantly decreased GSH level when compared to the control group.
On the contrary, it was also observed that ALT, AST, and MDA levels increased as a result of acrylamide administration. 
After lycopene treatment, it was observed that GSH level high significantly increased while ALT, AST, and MDA levels decreased when compared to acrylamide group and these results were nonsignificant as compared to controls.

B- Histopathological: Histopathological results supported the evidence of biochemical parameters analyzed in this study, as sections of rat liver treated with acrylamide showed significant

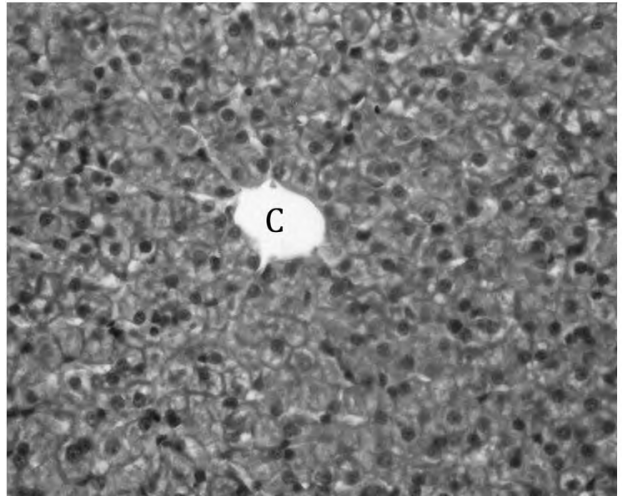

Fig. (1): A photomicrograph of a section from a rat's liver of control group showing the normal hepatic architecture of polygonal hepatocytes arranged in cords radiating from the Central Vein (CV). The cords are separated by sinusoidal spaces. (H \& E X400).

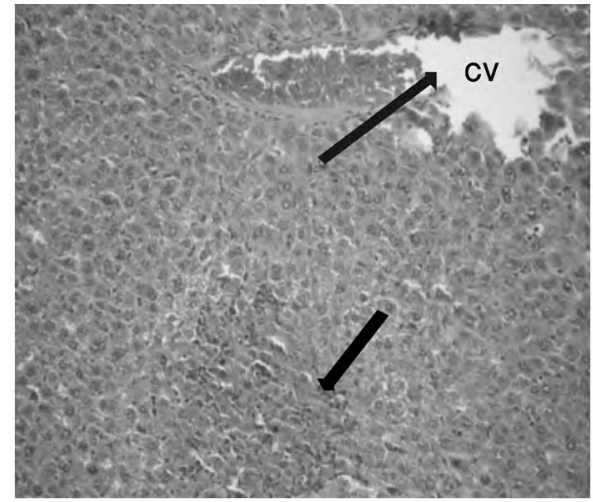

Fig. (3): A photomicrograph of a section from a rat's liver of acrylamide group showing severe congestion and dilation in central vein (CV) and hepatic sinusoids (blue arrow), necroinflammatory foci of hepatic lobule (black arrow). (H \& E X200). hepatotoxicity, characterized by dilatation and congestion of the blood sinusoids and central vein, necroinflammatory foci of hepatic lobule, as showed in Figs. $(2,3)$.

Liver sections in rats treated with acrylamide + lycopene showed improvement in the hepatic architecture, as showed by normal hepatic architecture in Fig. (4).

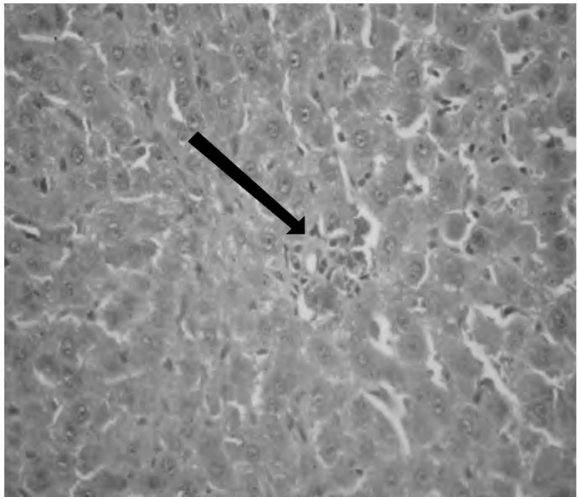

Fig. (2): A photomicrograph of a section from a rat's liver of acrylamide group showing hepatic necroinflammatory focus (arrow). (H \& E X400).

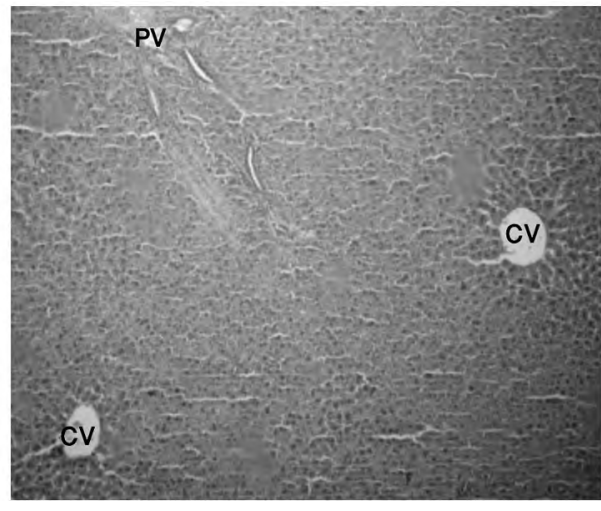

Fig. (4): A photomicrograph of a section from a rat's liver of acrylamide + lycopene group showing normal central vein $(\mathrm{CV})$, hepatic sinusoids and portal vein $(\mathrm{PV})$. (H \& E X200).

Table (2): Comparison between studied groups regarding alanine aminotransferase (ALT), aspartate aminotransferase (AST), malondialdehyde (MDA) and glutathione (GSH).

\begin{tabular}{|c|c|c|c|c|c|c|c|c|}
\hline \multirow{2}{*}{ Groups } & \multicolumn{2}{|c|}{$\operatorname{ALT}(\mathrm{U} / \mathrm{L})$} & \multicolumn{2}{|c|}{ AST (U/L) } & \multicolumn{2}{|c|}{ MDA (nmol/ml) } & \multicolumn{2}{|c|}{ GSH (mg/ml) } \\
\hline & Mean & $\pm \mathrm{SD}$ & Mean & $\pm \mathrm{SD}$ & Mean & $\pm \mathrm{SD}$ & Mean & $\pm \mathrm{SD}$ \\
\hline Controls & 24 & 3.3 & 21.8 & 2.9 & 5.55 & 1.05 & 4.60 & 1.21 \\
\hline Group IV (Acrylamide) & 110.83 & 2.81 & 109 & 4.9 & 18.8 & 0.12 & 1.1 & 0.14 \\
\hline Group V (Acrylamide + lycopene) & 26 & 3.4 & 23 & 5.6 & 6.1 & 1.03 & 4.3 & 1.17 \\
\hline F-test & 144.3 & & 145.2 & & 78.5 & & 83.9 & \\
\hline$p$ & $<0.01 \mathrm{HS}$ & & \multicolumn{2}{|c|}{$<0.01 \mathrm{HS}$} & \multicolumn{2}{|c|}{$<0.01 \mathrm{HS}$} & \multicolumn{2}{|c|}{$<0.01 \mathrm{HS}$} \\
\hline \multirow[t]{2}{*}{ Post hoc multiple comparisons } & \multicolumn{2}{|c|}{ Controls \# Group IV } & Contro & oup IV & \multirow{2}{*}{\multicolumn{2}{|c|}{ Group V \# Group IV }} & \multirow{2}{*}{\multicolumn{2}{|c|}{$\begin{array}{l}\text { Controls \# Group IV } \\
\text { Group V \# Group IV }\end{array}$}} \\
\hline & \multicolumn{2}{|c|}{ Group V \# Group IV } & \multicolumn{2}{|c|}{ Group V \# Group IV } & & & & \\
\hline
\end{tabular}

HS: High Significant.

\#: Significant with. 


\section{Discussion}

Acrylamide (ACR) is a chemical substance formed when starchy foods, such as potatoes and bread are cooked at high temperatures (above $120^{\circ} \mathrm{C}$ ). It can be formed when foods fried and baked [4]. High acrylamide levels have carcinogenic, genotoxic, neurotoxic and hepatotoxic effects on living organisms [5]. The present study designed to illustrate the biochemical and histopathological alterations of ACR on the liver of rats and the treatment of oxidative damage caused by acrylamide with the administration of a strong antioxidant, namely Lycopene.

Elevation of serum AST and ALT levels indicator of hepatocyte damage and indirectly reflects the failure of liver function [17]. In the present work, it was observed that acrylamide administration significantly increased AST, and ALT levels when compared to the control group.

Gedik et al., [18] also observed that AST and ALT levels increased as a result of acrylamide administration.

Al-Salmi [22] found that serum ALT and AST activities of ACR treated group were increased when compared with the control group.

The marked release of transaminases into the blood stream was due to hepatocyte necrosis with cell membrane degradation [23]

The present study revealed that ACR induced marked enhancement in MDA and decreased of GSH. These results are in agreement with Ahmed and Elmenoufy [10] who found that administration of ACR caused a significant enhancement in MDA level, due to oxidative stress with generation of free radicals which has been demonstrated to be a key mechanism in many ACR induced cell injuries. In addition, they showed that ACR significantly decreased GSH, which can be explained by the reaction of ACR with GSH, which in turn causes the depletion of GSH. The GSH is considered to be one of the most important non-enzymatic antioxidant in living cells [22]. Yousef and ElDemerdash [24] also noticed that acrylamide exerted damage effects and lipid peroxidation.

These findings were similar previously reported by Gedik et al., [18] and Al-Salmi [22] who observed that acrylamide administration significantly decreased GSH and increased MDA when compared to the control group.

Histopathological results supported the evidence of biochemical parameters analyzed in this study, as sections of rat liver treated with acrylamide showed significant hepatotoxicity, characterized by dilatation and congestion of the blood sinusoids and central vein, and necroinflammatory foci of hepatic lobule. The same histopathological changes of liver were observed in the study done by Jiang et al., [17].

These results are congruent with Gedik et al., [18] and Al-Salmi [22] who reported that liver sections of acrylamide group demonstrated inflammatory cell infiltration, hepatocellular necrosis and areas of hemorrhage.

Lycopene is a natural pigment, synthesized by plants and microorganisms. Red fruits and vegetables are the most common sources of Lyc, which exhibits the highest antioxidant activity among all dietary carotenoids. Therefore, nowadays, the potential role of Lyc in human health is beginning to be recognized, and the most important health benefits are hypothesized to occur through their ability to protect against oxidative damage [25] The aim of the present study was to demonstrate that Lyc is an effective antioxidant. In this study, it was observed after Lyc treatment that GSH level increased while AST, ALT, and MDA levels decreased and Lyc also ameliorates hepatic histopathological changes in rats induced by acrylamide. The results of Al-Salmi [22] also revealed that the Administration of LYC with ACR significantly decreased the ALT, AST and MDA level and increased GSH level when compared to ACR treated group.

Jiang et al., [17] found that treatment with Lyc is able to inhibit the elevation of liver function markers, and liver damage. Moreover, Lyc significantly raised GSH and reduced MDA, which suggesting that the activity of Lyc as antioxidant play a role in the mechanism of its hepatoprotective effect and ameliorative effect against acrylamideinduced hepatotoxicity.

\section{Conclusion and Recommendations:}

High acrylamide levels have carcinogenic, genotoxic, neurotoxic and hepatotoxic effects on living organisms. The current understanding of acrylamide toxic effects on the liver tissues of animals is somewhat limited; therefore, the present study examined the liver of rats, and clarified the possible alterations, due to the oxidative stress of acrylamide as many peoples exposed to this compound which are exceedingly produced during cooking food in very high temperature as fried or roasted food and almost fast food which is con- 
sumed excessively. Moreover, the present study showed the ability of Lycopene (LYC) that is widely found in red foods such as tomato, papaya, pink grape-fruit, pink guava, carrots and watermelon to ameliorate the hepatotoxicity of acrylamide, as oral administration of Lyc improved and remarkably decreased the levels of serum AST and ALT, increased the activities of antioxidant (GSH) and reduced (MDA) in rats. Further, Lyc improved liver histopathological changes. The increased antioxidant (GSH) level and the decreased lipid peroxides contents (MDA) are suggested to be due to important antioxidant mechanisms of Lyc in preventing the development of liver damage induced by ACR.

Therefore, intake of ACR could be limited and recommended with LYC when it is used with especially fast food or highly cooked food to decrease its toxicity.

\section{Acknowledgement:}

Our deep appreciation to the staff members of Forensic Medicine \& Clinical Toxicology, Anatomy and Pathology Departments, Faculty of Medicine, Benha University, for their cooperation. http://www. fmed.bu.edu.eg.

\section{References}

1- OHARA T., SATO T., SHIMIZU N., et al.: "Acrylic Acid and Derivatives". Ullman's Encyclopedia of Industrial Chemistry. Weinheim: Wiley-VCH, 2003.

2- ERKEKOGLU P. and BAYDAR T.: Acrylamide neurotoxicity. Nutr. Neurosci., 17: 49-57, 2014.

3- BOETTCHER M.I., SCHETTGEN B., KUTTING M., et al.: Mercapturic acids of acrylamide and glycidamide as biomarkers of the internal exposure to acrylamide in the general population. Mutat. Res./Genet. Toxicol. Environ. Mutagen., 580: 167-76, 2005.

4- JUNG M.Y., CHOI D.S., JU J.W., et al.: "A Novel Technique for Limitation of Acrylamide Formation in Fried and Baked Corn Chips and in French Fries". Journal of Food Science, 68 (4): 1287-90, 2003.

5- TAREKE E., RYDBERG P., ISHIZAKA M., et al.: "Analysis of acrylamide, a carcinogen formed in heated foodstuffs". J. Agric. Food Chem., 50 (17): 4998-5006, 2002.

6- MOTTRAM D.S., WEDZICHA B.L., DODSON A.T., et al.: "Acrylamide is formed in the Millard reaction". Nature. 419 (6906): 448-9, 2002.

7- VESPER H.W., BERNERT J.T., OSPINA M., et al.: "Assessment of the Relation between Biomarkers for Smoking and Biomarkers for Acrylamide Exposure in Humans". Cancer Epidemiology, Biomarkers \& Prevention, 16 (11): 2471-8, 2007
8- OLESEN P.T., OLSEN A., FRANDSEN H., et al.: "Acrylamide exposure and incidence of breast cancer among postmenopausal women in the Danish Diet, Cancer and Health Study". International Journal of Cancer, 122 (9): 2094-100, 2008.

9- BARBER D.S., HUNT J.R. and EHRICH M.F.: Metabolism, toxicokinetics and hemoglobin adduct formation in rats following subacute and subchronic acrylamide dosing. Neurotoxicology, 22: 3 41-53, 2001.

10-AHMED M.M. and ELMENOUFY G.: Ameliorative Effect of Ferulic Acid on Acrylamide Induced Inflammation and Oxidative Damage in Rat Testes. Research Journal of Pharmaceutical, Biological and Chemical Sciences, 7 (1): 396-400, 2016.

1 1- BOEIRA S.P., FILHO C.B., Del'FABBRO L., et al.: Lycopene treatment prevents hematological, reproductive and histopathological damage induced by acute zearalenone administration in male Swiss mice. Exp. Toxicol. Pathol., 66: 179-85, 2014.

12- TAKESHIMA M., ONO M., HIGUCHI T., et al.: Antiproliferative and apoptosis-inducing activity of lycopene against three subtypes of human breast cancer cell lines. Cancer Sci., 105: 252-7, 2014.

13- DATTA S., JAMWAL S., DESHMUKH R., et al.: Beneficial effects of lycopene against haloperidol induced orofacial dyskinesia in rats: Possible neurotransmitters and neuroinflammation modulation. Eur. J. Pharmacol., 771: 229-35, 2016

14- YONAR M.E.: The effect of lycopene on oxytetracyclineinduced oxidative stress and immunosuppression in rainbow trout (Oncorhynchus mykiss, W.). Fish Shellfish Immunol., 32: 994-1001, 2012.

15- SACHDEVA A.K. and CHOPRA K.: Lycopene abrogates Ap (1-42)-mediated neuroinflammatory cascade in an experimental model of Alzheimer's disease. J. Nutr. Biochem., 26: 736-44, 2015.

16- ABDUL-HAMID M. and SALAH M.: Lycopene reduces deltamethrin effects induced thyroid toxicity and DNA damage in albino rats. J. Basic Applied Zool., 66: 15563, 2013.

17- JIANG W., MEI-HUA G., XIN H., et al.: Hepatoprotective and antioxidant effects of lycopene on non-alcoholic fatty liver disease in rat, World J. Gastroenterol., 22 (46): 10180-8, 2016

18- GEDIK S., ERDEMLI M.E., YIGITCAN B., et al.: Hepatoprotective effects of crocin on biochemical and histopathological alterations following acrylamide-induced liver injury in Wistar rats. Biomedicine \& Pharmacotherapy, 95: 764-70, 2017.

19- CHATTOPADHYAY A., BISWAS S., BANDYOPADHYAY D., et al.: Effect of isoproterenol on lipid peroxidation and antioxidant enzymes of myocardial tissue of mice and protection by quinidine. Molec. Cell. Biochem., 245: 43-9, 2003.

20- BEUTLER E., DURON O., KELLY B., et al.: Improved method for the determination of blood glutathione. J. Lab. Clin. Med., 61: 882-8, 1963. 
21- LAMBERG S. and ROTHSTEIN R. (eds.): Laboratory Manual of Histology and Cytology. 2 nd ed., A.V.I. Publishing Company, West Port Connecticut, 137-40, 1978.

22- AL-SALMI F.A.: Ameliorative and Synergistic Effect of Red Raspberry and Lycopene Against Hepatotoxicity Induced by Acrylamide in Male Mice. International Journal of Pharmacology, 15: 166-76, 2019.

23- BAIRWA N.K., SETHIYA A., MISHRA S., et al.: Protective effect of stem bark of Ceiba Pentandra against paracetamol-induced hepatotoxicity in rats. Pharmacognosy Research, 2: 26-30, 2010.

24- YOUSEF M.I. and EL-DEMERDASH F.M.: Acrylamideinduced oxidative stress and biochemical perturbations in rats. Toxicology, 219: 133-41, 2006.

25- RAO A.V., FLESHNER N. and AGARWAL S.: Serum and tissue lycopene and biomarkers of oxidation in prostate cancer patients: A case-control study. Nutr. Cancer, 33: 159-64, 1999.

\section{التآثير المحسن لمادة الليكوبين على الآثار السمية الكبلدية للكاكريلامايل

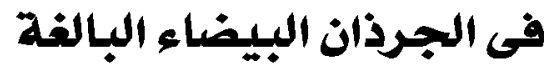

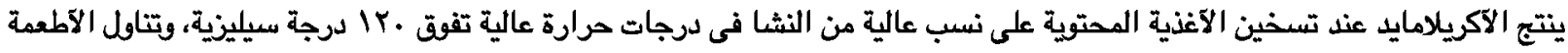

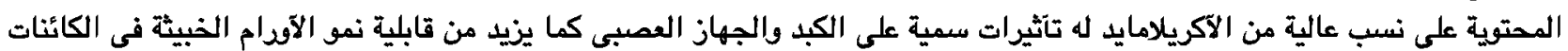

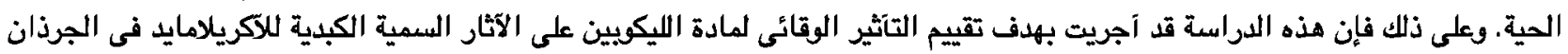
البيضاء البالغة والليكوبين مادة صبغية طبيعية موجودة على نطاق واسع فى الآغذية حمراء مثل الطماطلم والبطيخ والجوافة القية القرمزية وغيرها

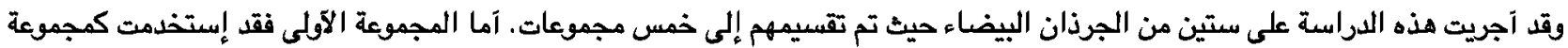

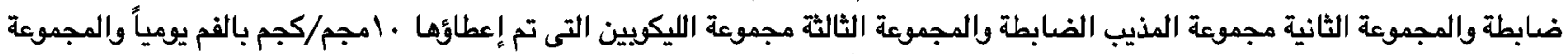

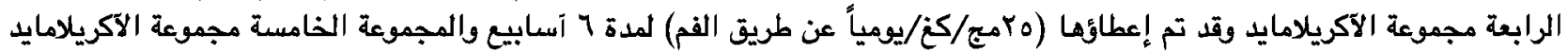

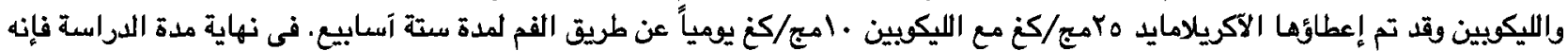

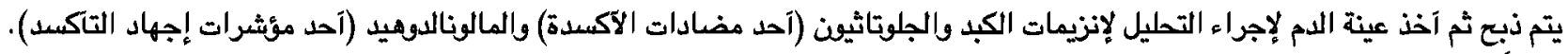

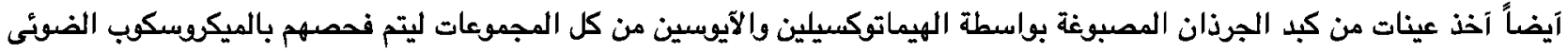

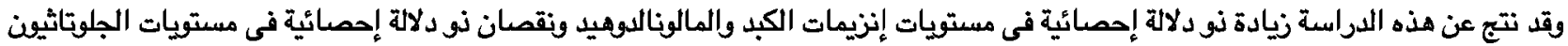

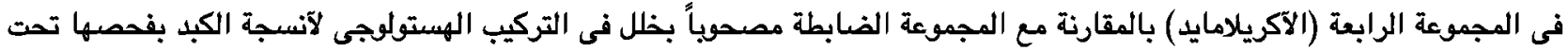

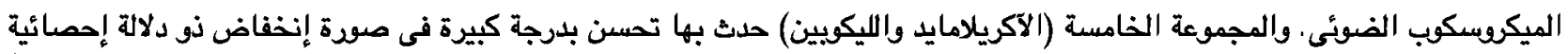

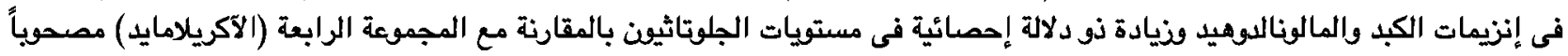

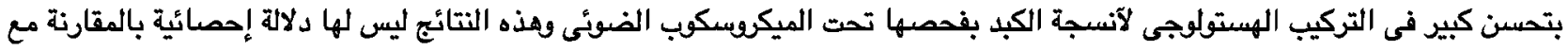

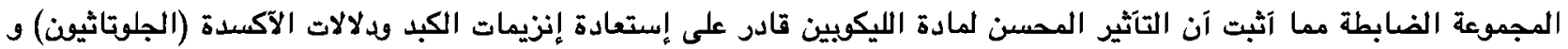

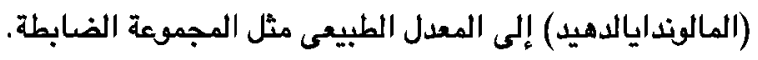
يوصى بالتوعية بمخاطر تسخين الآغذية النشوية فى درجات حرارة عالية على الكبد ودو الليكوبين كمحسن لهذه المخاطر. 